\title{
Prevalence of Trichomonas vaginalis in a male sexually transmitted disease clinic population by interview, wet mount microscopy, and the InPouch ${ }^{\mathrm{TM}} \mathrm{TV}$ test
}

\author{
K A Borchardt, Saleh Al-Haraci, Nino Maida
}

\begin{abstract}
Objective-To determine the prevalence of trichomoniasis in male patients from their urine at a Sexually Transmitted Disease (STD) Clinic using the InPouch ${ }^{\text {TM }}$ TV culture system.

Methods-Two hundred and four patients were examined for STD infections. Their ages ranged between 17 and 72 years. Depending on their clinical symptoms tests were ordered for Neisseria gonorrhoeae, chlamydia, and for syphilis. Each patient submitted a clean catch urine specimen for trichomonas testing. A $15 \mathrm{ml}$ aliquot of urine was centrifuged and a drop of the sediment examined microscopically. The remainder was cultured in the InPouch ${ }^{\mathrm{TM}} \mathrm{TV}$ test. Each pouch was examined at $24 \mathrm{~h}, 48 \mathrm{~h}$, and 5 days.

Results-Twenty-four of the 204 patients (12\%) .were culture positive for Trichomonas vaginalis and only three of these were wet mount positive.

Conclusion-The InPouch TM TV test demonstrated an epidemiological important infected male population that was not indicated by wet mount microscopy.
\end{abstract}

(Genitourin Med 1995;71:405-406)

Keywords: Trichomonas vaginalis; male; prevalence

Professor K A Borchardt.

Accepted for publication

9 August 1995

Patients positive for $T$ vaginalis

\begin{tabular}{|c|c|c|c|c|c|c|}
\hline \multirow[b]{2}{*}{ No } & \multirow{2}{*}{$\begin{array}{l}\text { Age } \\
\text { (years) }\end{array}$} & \multirow[b]{2}{*}{ Diagnosis } & \multicolumn{3}{|c|}{ Culture (+)Day } & \multirow[b]{2}{*}{ Wet Mount } \\
\hline & & & 1 & 2 & 3 & \\
\hline 1 & 72 & GI symptoms & + & + & + & + \\
\hline 2 & 58 & Urethritis & + & + & + & + \\
\hline 3 & 28 & Urethritis & - & + & + & - \\
\hline 4 & 16 & Urethritis & - & + & + & - \\
\hline 5 & 58 & Urethritis & + & + & + & - \\
\hline 6 & 21 & Urethritis & + & + & + & + \\
\hline 7 & 38 & Urethritis & + & + & + & - \\
\hline 8 & 36 & $\begin{array}{l}\text { Urethritis } \\
\text { Partner had Trich. }\end{array}$ & + & + & + & - \\
\hline 9 & 34 & Urethritis & + & + & + & - \\
\hline 10 & 35 & Partner had Trich. & - & - & + & - \\
\hline 11 & 30 & URTI & + & + & + & - \\
\hline 12 & 33 & Urethritis & + & + & + & - \\
\hline 13 & 31 & Urethritis & - & + & + & - \\
\hline 14 & 21 & Urethritis & + & + & + & - \\
\hline 15 & 26 & Urethritis & + & + & + & - \\
\hline 16 & 35 & Urethritis & + & + & + & - \\
\hline 17 & 24 & R/O Syphilis & + & + & + & - \\
\hline 18 & 43 & Partner had Trich. & - & + & + & - \\
\hline 19 & 42 & Urethritis & + & + & + & - \\
\hline 20 & 47 & Urethritis & - & + & + & - \\
\hline 21 & 25 & Urethritis & + & + & + & - \\
\hline 22 & 39 & Urethritis & - & + & + & - \\
\hline 23 & 47 & Partner had Trich. & - & - & + & - \\
\hline 24 & 34 & Urethritis & - & + & + & - \\
\hline \multicolumn{3}{|c|}{ Total Positives } & 15 & 22 & 24 & 3 \\
\hline
\end{tabular}

GI, gastrointestinal; URTI, upper respiratory tract infection; R/O, rule out

Patient 1 was diagnosed positive for syphilis and patients 4,21 , and 22 for GC.

\section{Introduction}

Contemporary clinical studies have demonstrated the significance of trichomoniasis. Trichomonas vaginalis has been associated with premature rupture of the membranes in pregnancy, low birth weight in neonates from an infected mother, and a potential increase in the exposure to the human immunodeficiency virus. $^{1-3}$ Infected females may develop mild to severe symptoms. Determination of the prevalence of trichomoniasis may be affected by the asymptomatic nature of the infections in 50\% of the females, in a majority of males, and by the self-limiting nature in males. ${ }^{45}$

This study was designed to determine the prevalence of $T$ vaginalis in a male population at a Sexually Transmitted Disease (STD) Clinic using urine sediment obtained from the patients specimen. The detection methods included a clinical history, slide microscopy, and the InPouch ${ }^{\mathrm{TM}}$ TV culture system (BioMed Diagnostics, San Jose, CA).

\section{Materials and methods}

The study included 204 male patients examined at the Richmond Health Center for STD, Richmond, CA. Patients attending this free evening clinic varied in ethnic origin, work ethic, and general health. Information was obtained retrospectively from all of the participating patients' charts. After a clinical examination, each patient submitted a clean catch urine specimen irrespective of his symptoms. Appropriate diagnostic tests were ordered by the physician depending on the patients symptoms. These tests included: gram stain of an urethral specimen, culture, antibiotic susceptibility testing including $\beta$-lactamase for Neisseria gonorrhoeae (GC), fluorescent antibody for chlamydia, and a VDRL for syphilis.

Specimen transport of urine to the laboratory was usually less than $30 \mathrm{~min}$. A $15 \mathrm{ml}$ aliquot of the urine was centrifuged at $700 \mathrm{~g}$ for $15 \mathrm{~min}$. One drop of sediment was examined microscopically on a $22 \times 22 \mathrm{~mm}$ coverslipped glass slide for approximately $2 \mathrm{~min}$ by an experienced microscopist (SAH). The remaining sediment was added to the InPouch TM test. The pouch was incubated at $37^{\circ} \mathrm{C}$ for $24 \mathrm{~h}$ before microscopic examination at $100 \mathrm{X}$ or $400 \mathrm{X}$. Each pouch was examined for approximately $2 \mathrm{~min}$. When necessary it was viewed at $48 \mathrm{~h}$ and 5 days incubation. The criteria for microscopic identification of $T$ vaginalis was determined by its characteristic morphology and motility. 


\section{Results}

The table presents the data for the 24 patients positive for $T$ vaginalis. Listed are their ages, significant clinical symptoms, results from culture and wet mount microscopy for $T$ vaginalis.

Ages of the patients ranged between 16 and 72 years. Nine were between the ages of 16 and 30,10 between 31 and 45, and 5 over 46 years. Eighteen of these patients had urethritis.

Of the 24 patients positive by culture, 15 were positive at $24 \mathrm{~h}(62 \%), 7$ at $48 \mathrm{~h}(29 \%)$, and 2 at 5 days ( $8 \%)$. The 3 wet mount positive specimens were culture positive at $24 \mathrm{~h}$. The 4 patients who had contact with an infected partner were wet mount negative but culture positive at $24 \mathrm{~h}, 48 \mathrm{~h}$, and 5 days. Three of the trichomonas positive patients were positive for gonorrhoea and one for syphilis.

Gonorrhoea was the most frequently diagnosed infection (in 53 of the 204 patients). Ten of the 204 patients were positive for a chlamydia infection.

\section{Discussion}

Although $T$ vaginalis persists most frequently in the sub clinical stage, it has been associated with a variety of various lower genitourinary infections in males such as nongonococcal urethritis and prostatitis. Asymptomatic carriers are an important reservoir of infection and diagnosis is unreliable based on either the clinical signs or symptoms presented by the patient. $^{6}$

This study was unable to use the first voided urine because of the evening clinic. Neither urethral swabs nor semen specimens were available for evaluation. It was important in this study to evaluate the sensitivity of the two tests with freshly voided specimens which might be useful in similar clinical situations.

Four of the 204 patients could have been expected by contact history to test positive for trichomoniasis, but they were only positive by culture. Twenty-one patients would have been undetected without culture. Only one of the four patients having contact with a trichomonad-positive partner was positive in 24 $\mathrm{h}$ while the other three required $48 \mathrm{~h}$. This suggests that there was a lower number of trichomonads in the specimens. Generation times of $T$ vaginalis in the pouch have been previously reported at approximately $4 \mathrm{~h}$ for the first $24 \mathrm{~h}$. $^{7}$

Because Krieger et al found 4/65 male trichomonad infections to be positive only by semen culture, this specimen still requires evaluation and contrasted to urine sediment with the pouch test. ${ }^{8}$

In vitro culture for $T$ vaginalis is considered the "gold standard" for the diagnosis of trichomoniasis. ${ }^{9}$ The results of this study indicated that freshly voided urine specimens from infected males may be cultured and produce positive tests when a first voided specimen is unavailable.

Only the patients who had contact with females diagnosed for the disease were initially treated. This study confirmed the importance of utilising a sensitive culture method for a clinical differentiation between the diagnosis of trichomoniasis and nongonococcal urethritis.

This work was presented in part at the American Society of Microbiology Meeting, May 21-3, Washington, DC 1995.

1 Cotch MF. Vaginal infection and prematurity study group carriage of Trichomonas vaginalis is associated with adverse pregnancy outcome (abstract 68). In program and abstract of the 36th Interscience Conference on Antimicrobial Agents and Chemotherapy (Atlanta) Washington, DC: American Society for Microbiology 1990.

2 Draper D, Parker R, Patterson E, et al. Detection of Trichomonas vaginalis in pregnant women with the InPouch TV culture system. F Clin Microbiol 1993;10: InPouch.

3 Laga M, Manoka A, Kivuvu M, et al. Non-ulcerative sexually transmitted diseases as risk factors for HIV-1 transmission in women: results from a cohort study. AIDS 1993;7:95-102.

4 Krieger JN, Verdon M, Siegel NJ, et al. Natural history of urogenital trichomoniasis in men. $\mathcal{F}$ Urol 1993;149: 1455-8.

5 McCormack WM. Sexually transmissible conditions other than gonorrhea and syphilis. In: Tice F, Sloan L (eds) Practice of Medicine: New York: Harper and Row, 1974; 3:1-16.

6 Krieger JN. Trichomoniasis men: old issues and new data Sexually Transmitted Diseases 1993;22:83-96.

7 Borchardt KA, Smith RF. An evaluation of the InPouch ${ }^{\mathrm{TM}}$ TV culture for diagnosing Trichomonas vaginalis infecTV culture for diagnosing Trichomonas
tion. Genitourin Med 1991;67:149-52.

8 Krieger JN, Jenny C, Verdon M, et al. Clinical manifestations of trichomoniasis in men. Ann Int Med 1993; 118:844-9.

9 Lossick JG. The diagnosis of vaginal trichomoniasis. $\mathcal{F} A M A$ 1988;67:149-52. 